\title{
Analysis of the Separating Performance of a Card Cleaner for Pepper Harvester using EDEM Software
}

\section{BYUM, Jun-Hee}

Department of Bio-Industrial Machinery Engineering, Chonbuk National University I Laboratory of Agricultural Machinery and Production Systems Design, Division of Bioproduction Environmental Sciences, Faculty of Agriculture, Kyushu University

NAM, Ju-Seok

Department of Bio-Industrial Machinery Engineering, Chonbuk National University | Laboratory of Agricultural Machinery and Production Systems Design, Division of Bioproduction Environmental Sciences, Faculty of Agriculture, Kyushu University

\section{CHOE, Jung-Seob}

Department of Precision Mechanical Engineering, Kyungpook National University | Laboratory of Agricultural Machinery and Production Systems Design, Division of Bioproduction Environmental Sciences, Faculty of Agriculture, Kyushu University

\section{INOUE, E i j i}

Department of Agro-environmental Science, Faculty of Agriculture, Kyushu University I Laboratory of Agricultural Machinery and Production Systems Design, Division of Bioproduction Environmental Sciences, Faculty of Agriculture, Kyushu University

他

https://doi.org/10.5109/1955404

出版情報：九州大学大学院農学研究院紀要. 63 (2)，pp.347-354，2018-09-01. Faculty of Agriculture, Kyushu University

バージョン :

権利関係 : 


\title{
Analysis of the Separating Performance of a Card Cleaner for Pepper Harvester using EDEM Software
}

\author{
Jun-Hee BYUM ${ }^{1}$, Ju-Seok NAM ${ }^{2}$, Jung-Seob CHOE ${ }^{3}$, Eiji INOUE ${ }^{4}$, \\ Takashi OKAYASU ${ }^{4}$ and Dae-Cheol KIM ${ }^{1,5 *}$
}

\begin{abstract}
Laboratory of Agricultural Machinery and Production Systems Design, Division of Bioproduction Environmental Sciences, Faculty of Agriculture, Fukuoka 812-8581, Kyushu University, Japan
\end{abstract} (Received May 1, 2018 and accepted May 8, 2018)

\begin{abstract}
In this study, we determined optimal operating conditions for a card-cleaner type separating system installable in a pepper harvester. We conducted a factorial experiment with an apparatus imitating the separating system. A particle-behavior analysis model using EDEM software was also developed, and the analysis results were compared with the factorial experiment results to demonstrate its validity. With the analysis model validated, an analysis with differing slope angle and number of shafts in the separating system was performed to specify the optimal operating conditions.

Upon comparing the factorial experiment and particle-behavior analysis results, the difference between separation ratios was approximately $1 \%$ and the difference between foreign material mixing ratios was under $3 \%$, confirming that the analysis model setup was valid. The optimization results using the analysis model revealed that the optimal conditions, in which separation ratio is over $95 \%$ and foreign material mixing ratio is $20 \%$ or lower, are achieved when the slope angle is $15^{\circ}$, the number of shafts is increased by 2 , and the rotation speed is $50 \mathrm{RPM}$.
\end{abstract}

Key words: pepper harvester, separating system, card cleaner, factorial experiment, EDEM, particle behavior analysis

\section{INTRODUCTION}

The pepper used as seasoning for various jjigae and kimchi as well as being the main ingredient for gochujang, has a profound relationship with traditional Korean culinary culture. It is a typical field crop with high demand in Korea, and constitutes over $2 \%$ of the total agricultural production value. Nevertheless, the cultivation area for pepper has diminished by nearly $30 \%$ from 45,000 ha to 32,000 ha in the 2013-2016 period (KOSTAT, 2016). The main reason behind this fall in cultivation area is a diminished rural workforce because of aging and subsequent increase in labor cost. The annual labor input for pepper cultivation is estimated to be around 11.47 million hours, and the highest majority of $61.4 \%$ of the annual labor input is attributed to the August-September harvest season.

Research on mechanizing pepper harvesters is under-

\footnotetext{
${ }^{1}$ Department of Bio-Industrial Machinery Engineering, Chonbuk National University, 567 Baekje-daero, Deokjin-gu, Jeonju, Jeollabuk-do, 54896, Republic of Korea

${ }^{2}$ Department of Biosystems Engineering, Kangwon National University, 1 Kangwondaehak-gil, Chuncheon, Gangwon-do, 24341, Republic of Korea

Department of Precision Mechanical Engineering, Kyungpook National University, Gajangdong, Sangju, Republic of Korea

${ }^{4}$ Department of Agro-environmental Science, Faculty of Agriculture, Kyushu University, 6-10-1 Hakozaki Higashi-ku, Fukuoka 812-8581, Japan

Institute for Agricultural Machinery \& ICT Convergence, Chonbuk National University, 567, Baekje-daero, Deokjin-gu, Jeonju-si, Jeollabuk-do, Republic of Korea.

* Corresponding Author (Email: dckim12@jbnu.ac.kr)
}

way, for labor saving of harvest being the most laborconsuming part of pepper cultivation. However, since foreign material such as stems, leaves, and soil is also collected along with peppers in mechanized pepper harvesting, additional steps are needed to separate out only the desired peppers. Research is also being carried out on separating systems to separate normal peppers and foreign material collected through the pepper harvester.

It is critical to determine the optimal operating conditions for the separating system, which show the highest separation performance in separating normal peppers and foreign material. The most accurate results would be obtained if the machine was built and subsequently tested for each operating condition; however, this would be impractical, and time and cost intensive. Instead, if we perform tests for some of the conditions and combine them with analysis using software, the optimal operating conditions can be found more efficiently.

In this study, we determined the optimal operating conditions for a card-cleaner type separating system by results on particle behavior analysis. A commercial analysis software on discrete element method (DEM) called EDEM was used in this study, because it specializes in analyzing the behavior of particles to produce a result similar to the behavior of real particles. We set up the factorial experiment apparatus for a card-cleaner type separating system, and experiments for some specific conditions were performed. The results were used to verify the analysis model constructed from the particle behavior analysis software, and the validated analysis model was used to find the optimal operating conditions with high pepper separation and low foreign material 
mixing ratios.

\section{MATERIALS AND METHODS}

\section{CARD-CLEANER TYPE SEPARATING SYSTEM}

A card-cleaner type separating system is used to separate the peppers and foreign materials supplied by the pepper harvester. It has the advantage of being able to be installed in a pepper harvester.

As for the working mechanism, the rotating squareshaped cards attached to the shafts agitate the pepper and foreign materials mixed with up and down motion of the pepper harvester, carrying them to the rear part of the separating system (conveying part). In the conveying process, small sizes of foreign material fall out from the gap between the cards. In the collector section located in the rear part of the separating system, the distance between the cards is adjusted so that only desirable peppers are collected (collecting part), and stems are discharged at the end of the separating system as their lengths are more than that of the peppers.

\section{FACTORIAL EXPERIMENT APPARATUS}

Figure 1 is the factorial experiment apparatus for the separating system that we built in this study. The dimensions of the separation system are $1440 \mathrm{~mm}$ (W) $\times$ $2190 \mathrm{~mm}(\mathrm{~L}) \times 370 \mathrm{~mm}(\mathrm{H})$ excluding the support, and cards are installed on a total of 15 square shafts. Sixty five cards are installed on odd-numbered shafts, while Sixty six cards are installed on even-numbered shafts. The slope angle of the apparatus is fixed at $15^{\circ}$, and the distance between the cards in the collector section is adjusted using spacers. The capacity of the driving motor is $1 \mathrm{HP}$, and the rotation speed of the shafts and the attached cards can be adjusted with the inverter. The major specifications of the experimental apparatus are detailed in Figure 2.

The cards attached to the shafts are made of composite plastic, and are $150 \mathrm{~mm}(\mathrm{~L}), 150 \mathrm{~mm}(\mathrm{~W})$, and 4.8 $\mathrm{mm}$ thick. One $26 \mathrm{~mm} \times 26 \mathrm{~mm}$ hole is bored into the center, and a circular flange with a diameter of $42 \mathrm{~mm}$ is fitted. The shape and major specifications of the cards are given in Figure 3 and Table 1, respectively. The cards in the conveying part are spaced evenly, $13.2 \mathrm{~mm}$ apart. The distance between the cards in the collecting

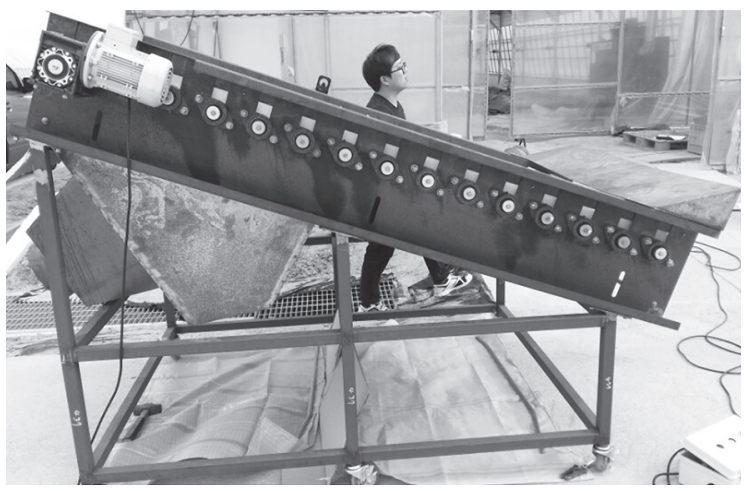

Fig. 1. Experimental apparatus for the separating system. part is set different from that of the conveying part, and only the peppers are sorted from the input and delivered to the collector. That is, the distances between the cards in the collecting part, which corresponds to shafts 11-13, are different from those in the conveying part, as illustrated in Figure 4.
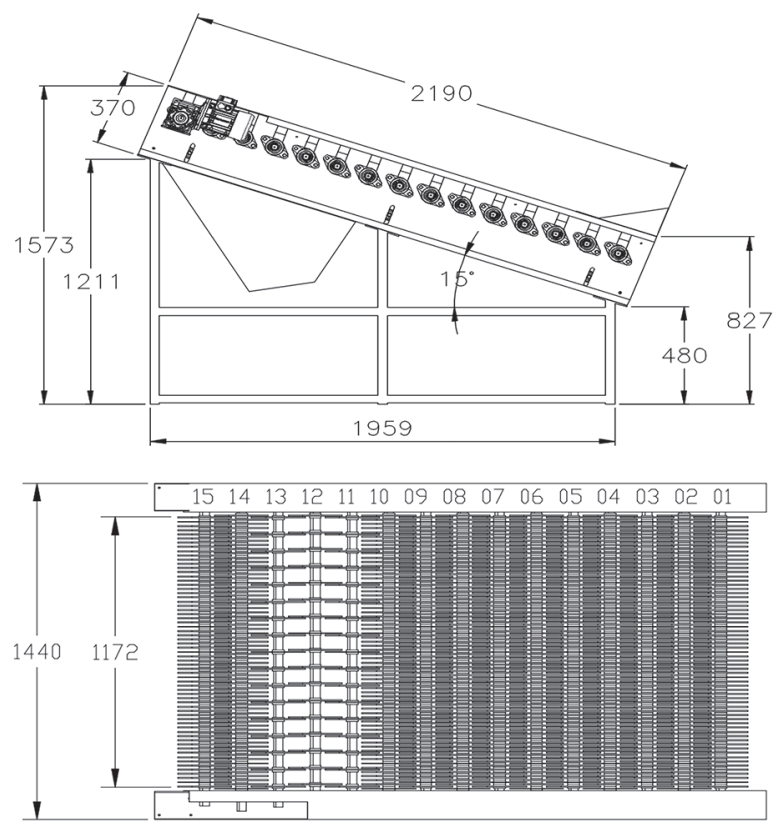

Fig. 2. Specifications of the experimental apparatus for the separating system.
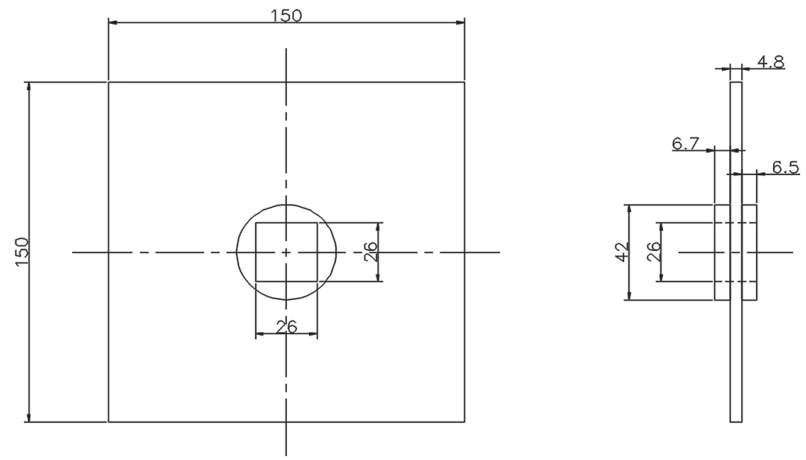

Fig. 3. Shape of cards used.

Table 1. Specifications of cards used

\begin{tabular}{cc}
\hline Attributes & Value (mm) \\
\hline Length of card & 150 \\
Width of card & 150 \\
Thickness of card & 4.8 \\
Distance between cards & 13.2 \\
Distance between shafts & 140 \\
\hline
\end{tabular}




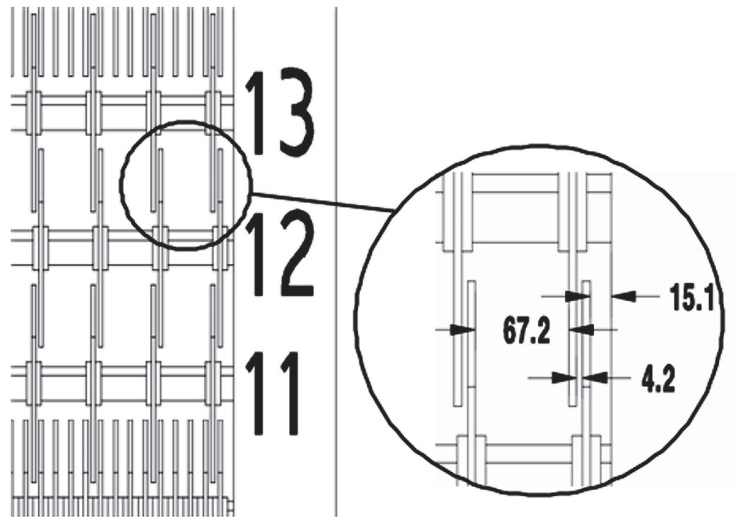

Fig. 4. Arrangement of cards in the collecting part.

\section{PEPPER SAMPLE}

The pepper sample used in the experiment is of the "AR legend" variety, grown in the greenhouse of the National Institute of Horticultural and Herbal Science of the Korean Rural Development Administration. The physical properties of the pepper plant and pepper fruit used as the sample were measured. The randomly selected 5 pepper plants and 10 pepper fruits from them were used. The physical property measurement results are listed in Tables 2 and 3.

The water content of the pepper sample stems, leaves, and fruits was measured. We followed the constant temperature drying method used in Choi's (2006) study as the method of measurement for the water content. Randomly selected pepper fruit, stems, and leaves were dried for $24 \mathrm{~h}$ at a constant temperature of $70^{\circ} \mathrm{C}$, and the weights before and after drying were compared. The water content of the pepper fruit, stems, and leaves was $87.61 \%, 75.60 \%$, and $80.20 \%$, respectively.

\section{FACTORIAL EXPERIMENT CONDITIONS}

The sample amounts to be used in the factorial experiments were determined considering the amount of products collected from the harvest work using the pepper harvester. After harvesting the 20 pepper plants,
$10,060 \mathrm{~g}$ of pepper fruit and $570 \mathrm{~g}$ of pepper stem were collected in the pepper harvester. The lengths of collected stems varied from $200 \mathrm{~mm}$ to $500 \mathrm{~mm}$. Thus, we prepared $10,060 \mathrm{~g}$ of pepper fruit and $190 \mathrm{~g}$ each of 250 $\mathrm{mm}, 350 \mathrm{~mm}, 450 \mathrm{~mm}$-long pepper stems as the factorial experiment sample. Figure 5 is a photo of the prepared sample of the pepper fruit and stem.

The main factor affecting the separation performance of a card-cleaner type separating system is the rotational speed of the cards attached to each shaft. Jo (2016) measured the separation ratios for different slope angles and card rotation speeds in a card-cleaner type separating system, and the highest separation ratio was achieved at a slope angle of $15^{\circ}$ and rotation speed of 50 RPM. With reference to this, the card rotation speed was set to three levels of 35, 50 and 65 RPM, and the slope angle was fixed to $15^{\circ}$. The sample input time for the separating system was set to $33.25 \mathrm{~s}$, which is the time it takes to harvest 20 pepper plants using a pepper harvester. The experiments were repeated thrice for each rotational speed.

\section{GENERATION OF ANALYSIS PARTICLES}

The particles representing the pepper fruit and stem should be generated before an analysis using EDEM. Among the physical properties listed in Table 3, the length, diameter, and weight were used to generate the particles. For each dimension, pepper particles with mean values (Pepper_m), pepper particles with values

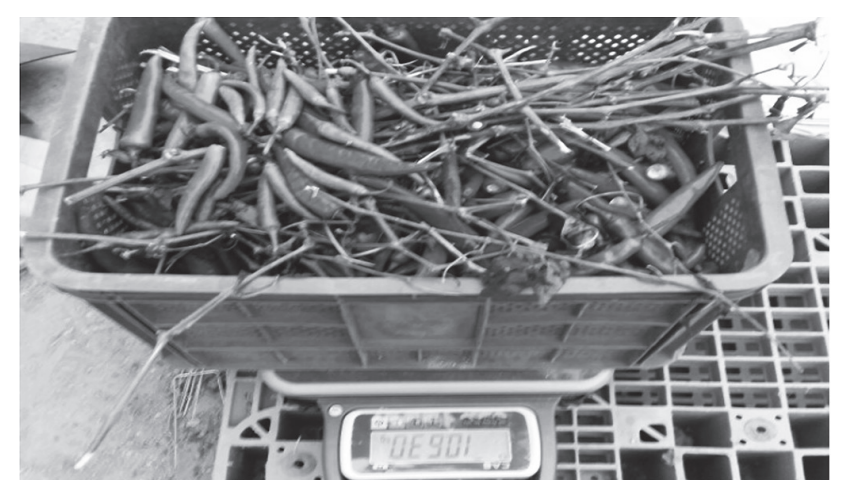

Fig. 5. Sample of pepper fruits and stems for factorial experiment.

Table 2. Physical properties of the pepper plants

\begin{tabular}{ccccc}
\hline Variety & $\begin{array}{c}\text { Length of pepper plant } \\
(\mathrm{mm})\end{array}$ & $\begin{array}{c}\text { Width of pepper plant } \\
(\mathrm{mm})\end{array}$ & $\begin{array}{c}\text { Length of pepper stem } \\
(\mathrm{mm})\end{array}$ & $\begin{array}{c}\text { Diameter of pepper stem } \\
(\mathrm{mm})\end{array}$ \\
\hline $\begin{array}{c}\text { Average } \\
\text { Standard deviation }\end{array}$ & 1120 & 770 & 290 & 21 \\
\hline
\end{tabular}

Table 3. Physical properties of the pepper fruit

\begin{tabular}{ccccc}
\hline Variety & $\begin{array}{c}\text { Length } \\
(\mathrm{mm})\end{array}$ & $\begin{array}{c}\text { Diameter } \\
(\mathrm{mm})\end{array}$ & $\begin{array}{c}\text { Weight } \\
(\mathrm{g})\end{array}$ & $\begin{array}{c}\text { Amount } \\
(\mathrm{ea} / \mathrm{plant})\end{array}$ \\
\hline Average & 104.3 & 19.8 & 12.7 & 33.8 \\
Standard deviation & 13.97 & 2.54 & 3.48 & 8.71 \\
\hline
\end{tabular}


Table 4. Specifications of particles for analysis using EDEM

\begin{tabular}{cccc}
\hline Sample & Length $(\mathrm{mm})$ & Diameter $(\mathrm{mm})$ & Weight $(\mathrm{g})$ \\
\hline Pepper_l & 118.3 & 22.4 & 16.2 \\
Pepper_m & 104.3 & 19.8 & 12.7 \\
Pepper_s & 90.4 & 17.3 & 9.3 \\
Stem_l & 450 & 7 & 28 \\
Stem_m & 350 & 6 & 12 \\
Stem_s & 250 & 5 & 5 \\
\hline
\end{tabular}

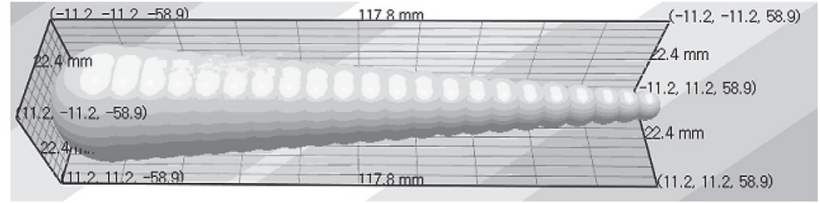

Fig. 6. Shape and size of pepper fruit particles (pepper_l).

equal to mean plus standard deviation (Pepper_l), and pepper particles with values equal to mean minus standard deviation (Pepper_s) were generated. Pepper stems were also created with their respective length, diameter, and weight. We used the factorial experiment values 250 , 350 , and $450 \mathrm{~mm}$ for the length, and the diameter and weight values were measured directly from the sample in the factorial experiment. We set the input amount of the pepper fruit and stem to be the same as the factorial experiment. The length, diameter, and weight of the generated analysis particles are tabulated in Table 4.

In EDEM, cylindrical particles are generated by linear alignment of spherical particles. The initial value of the diameter of the spherical particle constituting the pepper fruit particle is the specification diameter, and another sphere is added with distance of $5 \mathrm{~mm}$, while its

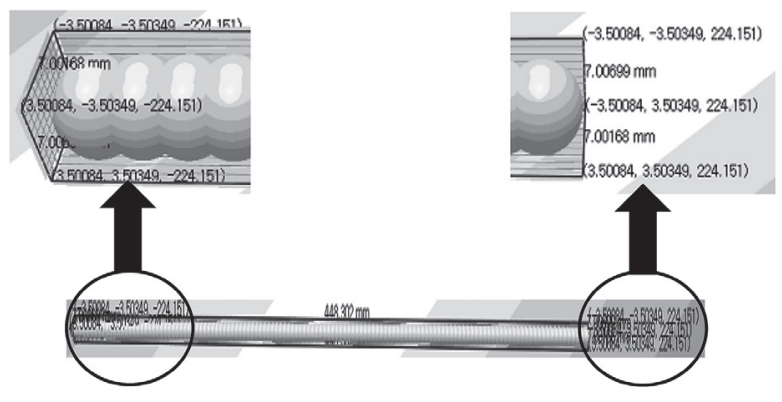

Fig. 7. Shape and size of stem particles (stem_l).

diameter is reduced by $0.8 \mathrm{~mm}$. The number of spherical particles used to generate the pepper fruit particle is 22 for Pepper_l, 20 for Pepper_m, and 17 for Pepper_s. Stem particles were generated by equidistantly aligning the same spherical particles. 99 spherical particles of diameter $5 \mathrm{~mm}$ were spaced $2.5 \mathrm{~mm}$ apart for Stem_s, 116 particles of diameter $6 \mathrm{~mm}$ were spaced $3 \mathrm{~mm}$ apart for Stem_m, and 127 particles of diameter $7 \mathrm{~mm}$ were spaced $3.5 \mathrm{~mm}$ apart for Stem_l. The shape and size of the pepper fruit and stem particles are shown in Figures 6 and 7.

Table 5. Measured physical properties required for analysis using EDEM

\begin{tabular}{|c|c|c|}
\hline \multirow{2}{*}{ Parameters } & \multicolumn{2}{|c|}{ Properties } \\
\hline & Pepper fruit & Stem \\
\hline Poisson's ratio & 0.295 & 0.291 \\
\hline Shear modulus $(\mathrm{Pa})$ & $4.62 \mathrm{E}+06$ & $1.28 \mathrm{E}+07$ \\
\hline Young's modulus (Pa) & $1.15 \mathrm{E}+07$ & $3.30 \mathrm{E}+07$ \\
\hline Density $\left(\mathrm{kg} / \mathrm{m}^{3}\right)$ & 601.8 & 980.4 \\
\hline \multicolumn{3}{|l|}{ Coefficient of restitution } \\
\hline With self & 0.38 & 0.22 \\
\hline With plastic & 0.40 & 0.15 \\
\hline With stem & 0.46 & - \\
\hline \multicolumn{3}{|l|}{ Coefficient of static friction } \\
\hline With self & 0.46 & 0.33 \\
\hline With plastic & 0.36 & 0.40 \\
\hline With stem & 0.31 & - \\
\hline \multicolumn{3}{|c|}{ Coefficient of rolling friction } \\
\hline With plastic & 0.043 & 0.034 \\
\hline
\end{tabular}




\section{MEASUREMENT OF PHYSICAL PROPERTIES FOR ANALYSIS}

In addition to the sizes of the analysis particles, input of physical properties such as Young's modulus and density is critical for analysis using EDEM. Tests were conducted in order to accurately derive the main physical properties of the pepper fruit and stem. We referred to the agricultural product's physical property measurement test by Cakir (2002) and Montellano (2012) in conducting the test, and the results are outlined in Table 5. We used the default value of 0.01 given in Boac's (2010) study for the rolling friction coefficient between the particles, based on the results by O'Sullivan (2004) that the coefficient is difficult to measure, and has little impact on the results for non-spherical particles.

\section{RESULTS AND DISCUSSION}

\section{RESULTS OF THE EXPERIMENT AND THE ANALYSIS}

The comparison between the values of the separation ratio obtained using the particle behavior analysis and factorial experiment is shown in Figure 8. The separation ratios in the factorial experiment increased as the rotational speed of the cards increased, and the highest separation ratio of $95.78 \%$ was observed at the rotational speed of 65 RPM. The separation ratios in the particle behavior analysis also increased with rotational speed, similar to in the factorial experiment results, and the highest separation ratio of $96.79 \%$ was obtained at the rotational speed of 65 RPM. The difference in separation ratios between the factorial experiment and particle behavior analysis was approximately $1 \%$, and this confirmed the high accuracy of the particle behavior analysis in predicting the separation ratio.

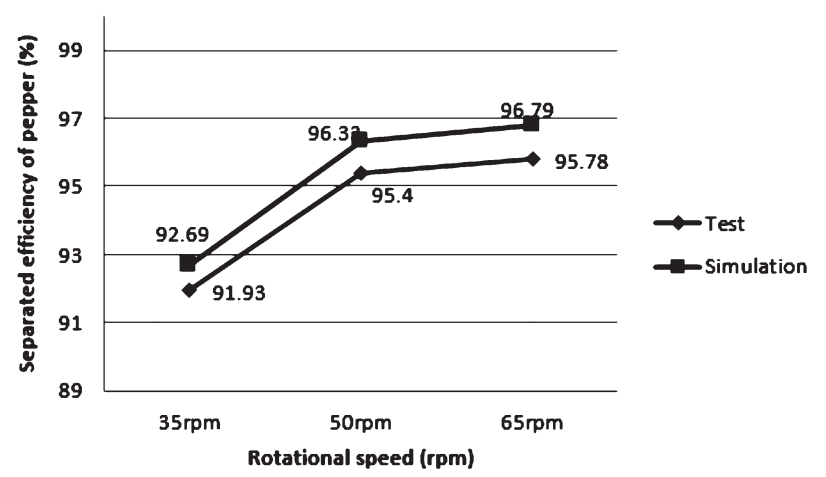

Fig. 8. Comparison of simulation and test results regarding separation efficiency.

Figure 9 shows the plots of the mixing ratio of foreign material in the particle behavior analysis and factorial experiment. The foreign material mixing ratio increased in both cases with increase in the rotational speed of cards, and the highest ratios were observed for the rotational speed of $65 \mathrm{RPM}$. The difference in foreign material mixing ratios between the factorial experi- ment and particle behavior analysis was approximately less than $3 \%$, justifying that the particle behavior results can also predict the foreign material mixing ratios with high accuracy.

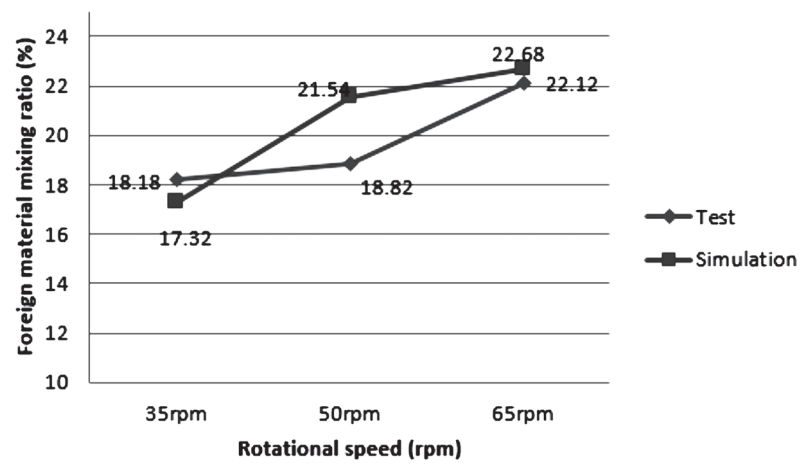

Fig. 9. Comparison of simulation and test results of foreign material mixing ratio.

\section{SEPARATION PERFORMANCE IMPROVEMENT MEASURES}

The separation performance can be regarded as superior when the separation ratio is high and the foreign material mixing ratio is low. In cases where the foreign material mixing ratio is high, additional work is needed in the pepper separation process regardless of the separation ratio. The slope angle and the number of shafts of the separating system were set as factors in the particle behavior analysis to find the operating condition with both high separation ratio and low foreign material mixing ratio. The analysis results were comparatively analyzed, and conditions in which the separation ratio is $95 \%$ or higher and the foreign material mixing ratio is under $20 \%$ were derived.

\section{CHANGES IN SLOPE ANGLE OF THE SEPARATING SYSTEM}

Figure 10 shows time-lapse images comparing separating systems with $5^{\circ}$ and $15^{\circ}$ slope angles when the rotational speed of the card cleaners is 65 RPM. Figure 11 is a graph comparing the separation ratios between $5^{\circ}, 15^{\circ}$, and $25^{\circ}$ slope angles for each rotational speed. The highest separation ratios appeared in the $15^{\circ}$ slope angle for all rotational speeds. A separation ratio of $95 \%$ or higher was obtained in the following conditions: slope angle of $15^{\circ}$ and rotational speed of 50 or 65 RPM. For all slope angles, the separation ratios increased at faster rotational speeds.

Figure 12 is a chart comparing the foreign material mixing ratio to separating system slope angle for different rotational speeds. The foreign material mixing ratios were $20 \%$ or more when the rotational speed was 50 or $65 \mathrm{RPM}$ and the slope angle was $15^{\circ}$, suggesting the impossibility of satisfying the $95 \%$ separation ratio and less-than-20\% foreign material mixing ratio condition by changing the slope angle alone. 


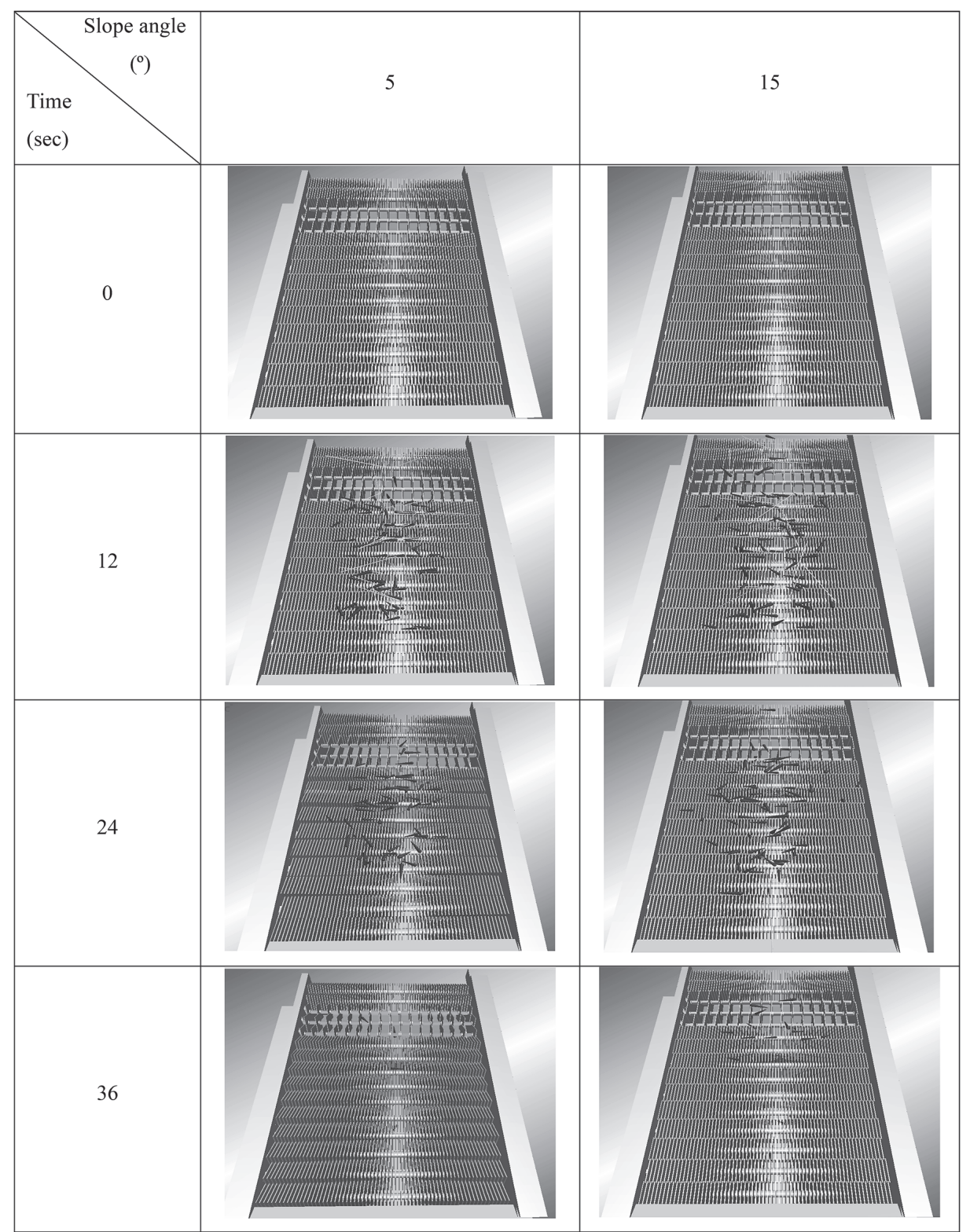

Fig. 10. Time-lapse images of the EDEM results for $5^{\circ}$ and $15^{\circ}$ slope angles at 65 RPM.

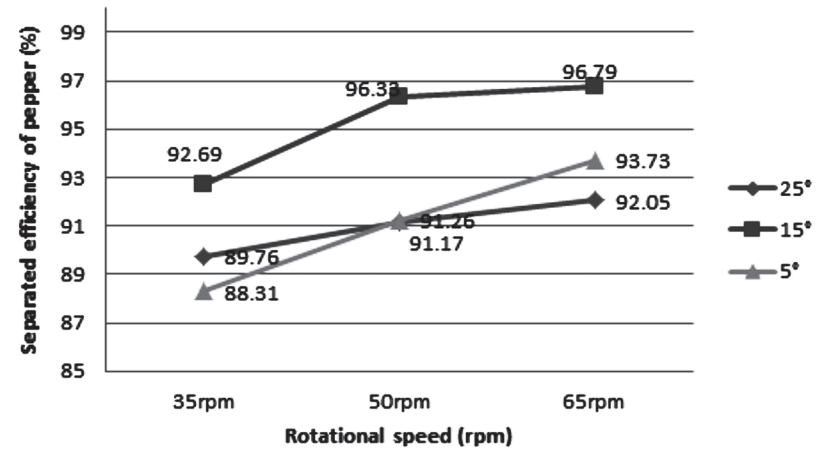

Fig. 11. Results of the separation efficiency of peppers based on the slope angle.

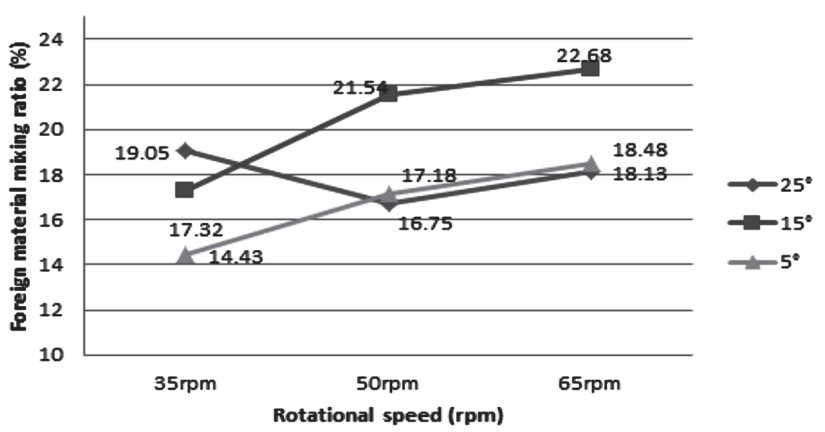

Fig. 12. Values of the foreign material mixing ratio based on the slope angle. 


\section{CHANGES IN THE NUMBER OF SHAFTS OF THE SEPARATING SYSTEM}

In Figure 13, the separation ratios are compared when the number of shafts stayed the same, increased by 2 , or decreased by 2 . The comparison was performed for each rotational speed at a $15^{\circ}$ slope angle, where the highest separation ratios had been recorded. The highest separation ratio of $96.89 \%$ was seen when the number of shafts in the separating system was increased by 2 and the rotational speed was 50 RPM. For all number of shafts, the separation ratio increased with a rotational speed increase from 35 RPM to 50 RPM, but it showed no significant differences for the increase from $50 \mathrm{RPM}$ to 65 RPM. The separation ratio reached $95 \%$ or higher at the rotational speeds of 50 and $65 \mathrm{RPM}$, regardless of the number of shafts.

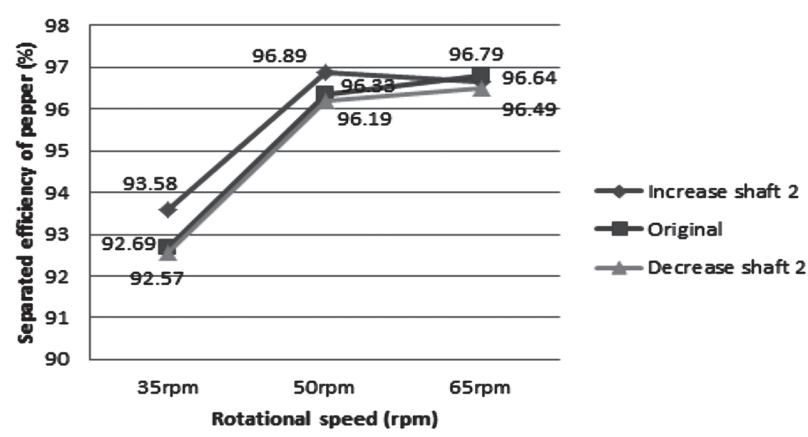

Fig. 13. Results of the separation ratios of peppers based on number of shafts at a $15^{\circ}$ slope angle.

In Figure 14, the foreign material mixing ratios at a $15^{\circ}$ slope angle for different numbers of shafts were compared for each rotational speed. The lowest foreign material mixing ratio of $12.83 \%$ was achieved when the number of shafts was increased by 2 in the rotating system, and the rotational speed was 35 RPM. The foreign material mixing ratios decreased for each rotational speed compared to the control when the number of shafts in the separating system increased by 2 , all achieving ratios under $20 \%$. On the other hand, the foreign material mixing ratios increased by $3-7 \%$ compared to the control when the number of shafts in the separating system was

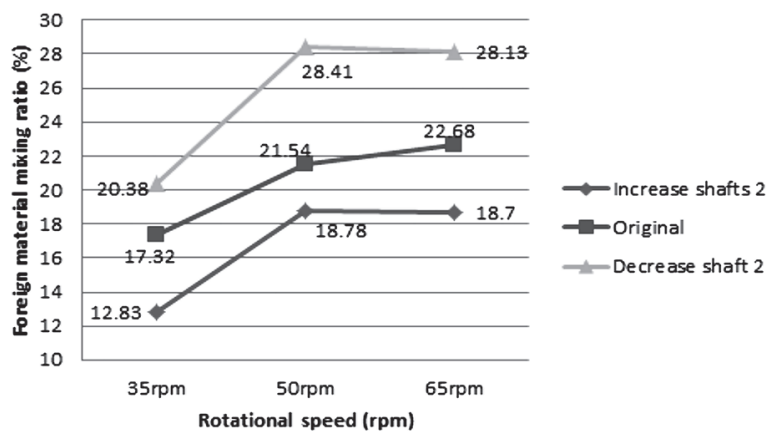

Fig. 14. Results of the foreign material mixing ratio based on number of shafts at $15^{\circ}$ slope angle. decreased by 2 . In summary, a combination of conditions $-15^{\circ}$ slope angle, increase in number of shafts by 2 , and rotational speed of $50 \mathrm{RPM}$ - formed the best possible conditions for separation ratio over $95 \%$ and foreign material mixing ratio under $20 \%$, scoring a separation ratio of $96.89 \%$ and foreign material mixing ratio of $18.78 \%$.

\section{SUMMARY AND CONCLUSIONS}

In this study, optimal operating conditions for a cardcleaner type separating system installable in a pepper harvester were determined. A factorial experiment apparatus mimicking a pepper harvester was designed and fabricated, and the factorial experiment was conducted. The factorial experiment results were compared with the analysis results obtained from particle behavior analysis software in order to verify the analysis model. Finally, the verified analysis model was used to derive optimal operating conditions with both high separation ratio and low foreign mixing material ratio. Slope angle and the number of shafts of the separating system were set as the factors for operating conditions.

The results of the comparison of the factorial experiment and particle behavior analysis demonstrated that the difference between separation ratios was approximately $1 \%$ and the difference between foreign material mixing ratios was under $3 \%$. Thus, the analysis model setup was capable of predicting the separation ratio and foreign material mixing ratio with high accuracy.

Particle behavior analysis was performed using the analysis model, with varying slope angle and number of shafts. The slope angle conditions were $5^{\circ}, 15^{\circ}$, or $25^{\circ}$, and the conditions for the number of shafts were: default, increase by 2 , or decrease by 2 . The analysis results revealed that optimal conditions, wherein the separation ratio is $>95 \%$ and foreign material mixing ratio is $<20 \%$ are obtained when the slope angle is $15^{\circ}$, the number of shafts is increased by 2 , and the rotation speed is $50 \mathrm{RPM}$.

\section{ACKNOWLEDGEMENT}

This work was supported by the Korea Institute of Planning and Evaluation for Technology in Food, Agriculture, Forestry and Fisheries(IPET) through Agriculture, Food and Rural Affairs Research Center Support Program, funded by Ministry of Agriculture, Food and Rural Affairs(MAFRA)(716001-7) and by the research funds of Chonbuk National University in 2018.

\section{REFERENCES}

Boac, J. M., M. E. Casada, R. G. Maghirang and J. P. Harner. 2010 Material and Interaction Properties of Selected Grains and Oilseeds for Modeling Discrete Particles. American Society of Agricultural and Biological Engineers, 53(4): 1201-1216

Cakir, E., F. Alayunt and K. Özden. 2002 A Study on the determination of Poisson's ratio and Modulus of elasticity of some onion varieties. Asian Journal of Plant Sciences 1(4): 376378

Choi, Y. 2006 Development of Machine Harvester for Pepper. DS thesis. Gwangju, Chonnam, Chonnam National University, Department of Agricultural Engineering, Korea 
Jo, Y. J. 2016 An Experimental Study on Separating Performance of Card Cleaner for Pepper Harvester. Master's thesis, Chonbuk National University, Department of Agricultural Engineering. Korea.

KOSTAT 2016. 2016 crop production statistics. http://kostat. go.kr. (in Korean)

Montellano, C. G., A. Ramirez, J. M. Fuentes and F. Ayuga 2012 Numerical effects derived from en masse filling of agricultural silos in DEM simulations. Computer and Electronics in Agriculture, 81: 113-123

O'Sullivan, C., J. D. Bray and M. Riemer 2004 Examination of the response of regularly packed specimens of spherical parti- cles using physical tests and discrete element simulations. Journal of Engineering Mechanics 130(10):1140-1150.

\section{AUTHOR CONTRIBUTIONS}

J. Byun designed the study, performed the experiments, analyzed the data and wrote the paper. J. Nam performed the statistical analysis. J. Choe, E. Inoue and T. Okayasu participated in the design of the study. D. Kim designed the study, wrote the paper and supervised the work. All authors assisted in editing of the manuscript and approved the final version. 